\title{
Delay discounting of compliance with containment measures during the COVID-19 outbreak: a survey of the Italian population
}

\author{
Mattia Nese ${ }^{1} \cdot$ Greta Riboli $^{2,3}$ (1) $\cdot$ Gianni Brighetti $^{3} \cdot$ Valentina Sassi $^{3} \cdot$ Elvira Camela $^{1} \cdot$ Gabriele Caselli $^{3,4}$. \\ Sandra Sassaroli ${ }^{3,4} \cdot$ Rosita Borlimi $^{3}$
}

Received: 28 April 2020 / Accepted: 16 May 2020 / Published online: 4 June 2020

(C) Springer-Verlag GmbH Germany, part of Springer Nature 2020

\begin{abstract}
Aim Unprecedented community containment measures were taken following the recent outbreak of COVID-19 in Italy. The aim of the study was to explore the self-reported future compliance of citizens with such measures and its relationship with potentially impactful psychological variables.

Subjects and methods An online survey was completed by 931 people (18-76 years) distributed across the Italian territory. In addition to demographics, five dimensions were measured: self-reported compliance with containment measures over time (today, at 7, 14, 30, 60, 90, and 180 days from now) at three hypothetical risk levels (10, 50, 90\% of likelihood of contracting the COVID-19), perceived risk, generalized anxiety, intolerance of uncertainty, and relevance of several psychological needs whose satisfaction is currently precluded.

Results The mean compliance scores follow a hyperbolic-like curve, decreasing over time for the lowest level of risk (10\%), whilst they tend to flatten for $\geq 50 \%$ risk $(90 \%)$. Significantly higher levels of anxiety, intolerance of uncertainty, and perceived risk were reported by women compared to men $(p<0.001$ for each variable). Outdoor sports was the only need associated with the discounting rate of compliance $\left(r_{s}=-0.08, p=0.018\right)$.

Conclusion The duration of containment measures plays a crucial role in tackling the spread of the disease as people will be less compliant over time. Psychological needs of citizens impacting on the compliance should be taken into account when planning an easing of the lockdown, along with interventions for protecting vulnerable groups from mental distress.
\end{abstract}

Keywords COVID-19 C Compliance $\cdot$ Community containment $\cdot$ Delay discounting $\cdot$ Anxiety

\section{Background}

In December 2019, an outbreak of pneumonia was reported in Wuhan, Hubei Province, China, whose cause was subsequently linked to a previously unknown virus named severe acute respiratory syndrome coronavirus 2 (SARS-CoV-2). In many cases, the novel coronavirus disease (COVID-19) causes a

Greta Riboli

g.riboli@milano-sfu.it

1 Department of Psychology, University of Bologna, Bologna, Italy

2 Faculty of Psychology, Sigmund Freud University, Vienna, Austria

3 Faculty of Psychology, Sigmund Freud University, Ripa di Porta Ticinese 77, 20143 Milan, Italy

4 Studi Cognitivi, Post Graduate Cognitive Psychotherapy School, Milan, Italy series of symptoms including fever, cough, myalgia, and shortness of breath, although in other cases it can be totally asymptomatic. In the most severe forms of infection, the clinical conditions can result in interstitial pneumonia, multiorgan failure, and eventually death (WHO 2020; Mohammadi et al. 2020; Zhang et al. 2020). COVID-19 is primarily transmitted through direct contact with infected subjects by means of droplets and nebulized saliva corpuscles propagated through sneezing and coughing, which are subsequently inhaled ( $\mathrm{Li}$ et al. 2020). The incubation period ranges from 3 to 14 days, potentially hiding the disease from clinical tests during that period and thus enhancing the risk of spreading it unknowingly (Jin et al. 2020).

Italy was the first European country to report a widespread outbreak of COVID-19 at the end of February 2020. The rapidly evolving situation led the Italian government to take dramatic containment measures. On 9 March 2020, a Decree of the Italian Prime Minister declared a nationwide lockdown 
meant to reduce the probability of the person-to-person spread of disease linked to social aggregation. The Decree (named "I stay at home") includes community-wide containment measures that affect the daily life of population at all levels in an unprecedented way. According to this, people are not allowed to leave their home except for the following proven necessities: going to work, buying food, helping other people with special needs, and receiving medical cares. The violation of the restrictions is sanctioned with a fine. The companies producing non-indispensable goods (51.3\% of the total) are forced to close their facilities. It is estimated that 7,784,000 people (33.3\% of the total workers) either began to work remotely from their houses or stopped working completely (Italian National Institute of Statistics, March 26th 2020). Most of the public spaces involving gathering of people (e.g., schools, restaurants, shops, hotels) were closed.

In this scenario, the success in arresting the spread of the disease may largely depend on the compliance of people with the strict rules limiting their personal freedom. However, compliance can be influenced by several factors both positively and negatively. For example, compliance could be enhanced by the perceived risk of being infected (or infecting others) while it could be weakened by loss of the usual routine and reduced social and physical contact. In addition, time plays a crucial role given that the duration of restrictions is linked to increased negative psychological effects. In the selected context, the duration of containment measures was unpredictable as it was extended weeks by weeks according to the evolution of contagion, creating a climate of high uncertainty. Thus, to predict the future compliance of people to containment measures, it is fundamental to understand its temporal dimension in relation to other psychological aspects.

Making profitable choices is fundamental for adaptation to the environment at all levels. However, humans tend to prefer immediate but smaller rewards over larger ones in the future, even when waiting would yield greater profits than pursuing immediate feelings (Rosati et al. 2007; Samuelson 1937). This notion, known as delay discounting (also temporal discounting or time discounting), has been extensively studied to explain decision-making processes, not only in the field of economic psychology, using monetary rewards, but also in association with healthy behaviours (Lawless et al. 2013; Odum et al. 2020).

Delay discounting has been proposed as a general psychological phenomenon underlying a wide range of maladaptive behaviours (Amlung et al. 2019; Bickel et al. 2019) such as substance abuse (Barlow et al. 2017), poor health behaviour, unhealthy food consumption (Garza et al. 2016), obesity (Amlung et al. 2016; Barlow et al. 2016), infrequent physical activity, not wearing sunscreen (Daugherty and Brase 2010), texting while driving (Hayashi et al. 2016), pathological gambling (Steward et al. 2017), and risky sexual behaviours (Johnson et al. 2015) and other behaviours (Story et al. 2014).
Moreover, higher rates of discounting based on treatment risks are associated with poor treatment adherence in multiple sclerosis (Bruce et al. 2018) while lower rates are associated with healthy lifestyle behaviours in cancer survivors (Sheffer et al. 2018).

In light of all these considerations, we could model the compliance with containment measures in the context of the current pandemic in Italy using an intertemporal risk-benefit trade-off framework.

Individuals can decide how to behave within a range of possibilities going from the complete avoidance of any unnecessary social contact (thus reducing the probability of infection) to the satisfaction of the need of physical contact that implies violation of the containment measures. While the positive effects of social distancing are potential and only visible in a relatively long (and undefined) term (weeks, months), the gratification of meeting other people would be immediate. It is worth noting that the punishments for violating community containment are not a sufficient deterrent per se, as the high number of fines registered during the first 3 weeks confirm (> 170,000 between 11 March and 4 April 2020, Interior Ministry).

In this view, several psychological variables could influence the delay discounting rate of compliance with the restrictions, such as anxiety and subjective perceived risk. For example, Jones and Salathé (2009) showed that self-reported anxiety over the epidemic of virus H1N1 in 2009 mediated the likelihood that people engage in protective behaviours, such the use of protective masks and better hygienic habits. A similar study had found that anxiety was associated with following recommended preventive behaviours after an outbreak of SARS in 2003 (Leung et al. 2005).

Previous studies have shown that perceived risk and anxiety are associated with self-reported compliance with preventive measures during disease outbreaks (Bults et al. 2011; Cava et al. 2005).

A recent study examined the degree of understanding and adhesion of 3452 Italian citizens in relation to the directives of the Prime Minister's Decree "I stay at home" using an online survey (Barari et al. 2020). The results showed that the majority of the respondents said they complied with the new regulations. In particular, the elderly reported higher compliance levels than young adults. Also, vulnerable groups reported higher level of anxiety. These data provide useful initial information about the behavioural and psychological impact of containment measures.

Given the important role of community containment measures in the containment of the COVID-19 pandemic and the role of Italy as a precursor in the adoption of these measures, it appears crucial to gain insight into the future trend of compliance to predict the outcomes and to inform subsequent decisions in the management of the emergency.

Consequently, this study aims to explore the future trend of compliance with community containment using an 
intertemporal choice paradigm, hypothesizing that compliance is time-dependent and susceptible to a delay discounting phenomenon. We also hypothesized that the temporal discounting rate would be associated with the urge to satisfy a number of psychological needs (e.g., meeting friends) and the perceived risk of contracting COVID-19. Finally, we collected data on the level of anxiety and intolerance of uncertainty to see how different groups are impacted by the situation. To our knowledge, this is the first study to explore compliance with containment measures during a pandemic within a delay discounting framework.

A delay discounting curve is hypothesized to describe the compliance with containment measures with lower discount rates for higher hypothetical probability of contracting COVID-19. Relationships among delay discounting and perceived risk, anxiety, intolerance of uncertainty, and psychological needs will be explored.

Please note that the use of the generic term quarantine has been avoided to avoid confusion with the forced isolation of confirmed positive or suspected cases of COVID-19. Instead, the terms containment measures and community containment are used throughout the article to refer to the series of restrictions intended to arrest the spread of the disease (see WilderSmith and Freedman 2020).

\section{Methods}

An online survey was developed to explore the prospective self-reported compliance and several potentially linked psychological dimensions. Respondents were recruited through advertising of the survey on two websites and social platforms from 29 March to 4 April 2020. The data collection time window was kept relatively short so that the responses would be consistent and to avoid possible confounding effects due to changes in the current situation. Informed consent was obtained from each participant at the beginning of the survey. Ethics approval was obtained by the Ethics Committee of Sigmund Freud University in accordance with the ethical standards of the Declaration of Helsinki.

\section{Measures}

Demographics Demographic characteristics were collected including gender, age, level of education, annual income, and location (region and city).

Delay discounting task The compliance with containment measures (in particular, staying at home) over time was quantified using a questionnaire inspired by the Medical Decision Making Questionnaire (MDMQ) proposed by Bruce and colleagues (2016). A series of different scenarios was presented in which people had to rate the acceptability of interrupting the isolation (and consequently resume interrupted daily life activities) using a 5-point Likert scale from "totally unacceptable" to "totally acceptable". Here, the term isolation referred to the ban on leaving the house except for the reasons specified by the law. A range of three different levels of hypothetical probability of contracting COVID-19 was presented (10, $50,90 \%$ ), and within each level, seven different time points were proposed $(0,7,14,30,60,90,180$ days from now). The resulting 21 items were presented adapting the following statement: "Interrupting the isolation in ... days in your area would give you a ...\% chance of contracting the COVID-19. How acceptable do you think the decision to terminate the isolation is?" It is argued that asking for the acceptability of interrupting the isolation would more likely elicit thinking about psychological needs compared to asking directly the degree of compliance.

Perceived risk Perceived risk was assessed by asking the subjects to subjectively predict the likelihood of contracting COVID-19 in their living area at each of the seven abovementioned time points, using a 4-point Likert scale ranging from 1 (very improbable) to 4 (very probable).

Psychological needs A set of questions concerning five proposed psychological needs that may be no longer satisfied because of the containment measures was presented: meeting the partner, meeting friends, going to work as usual, doing outdoor sports, engaging in recreational activities in public places (bars, restaurants, cinemas, theatres, etc.). For each of the above-mentioned psychological needs, participants were

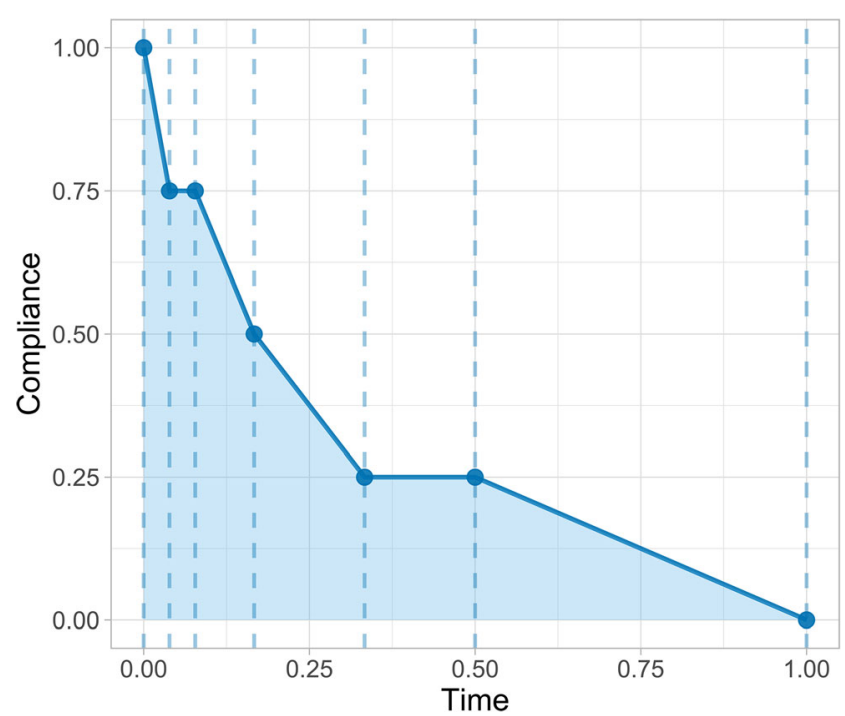

Fig. 1 Area under the curve (AUC) computed with a trapezoidal numerical integration. Points correspond to the degree of compliance for each of the seven considered times points represented by the vertical dashed lines 


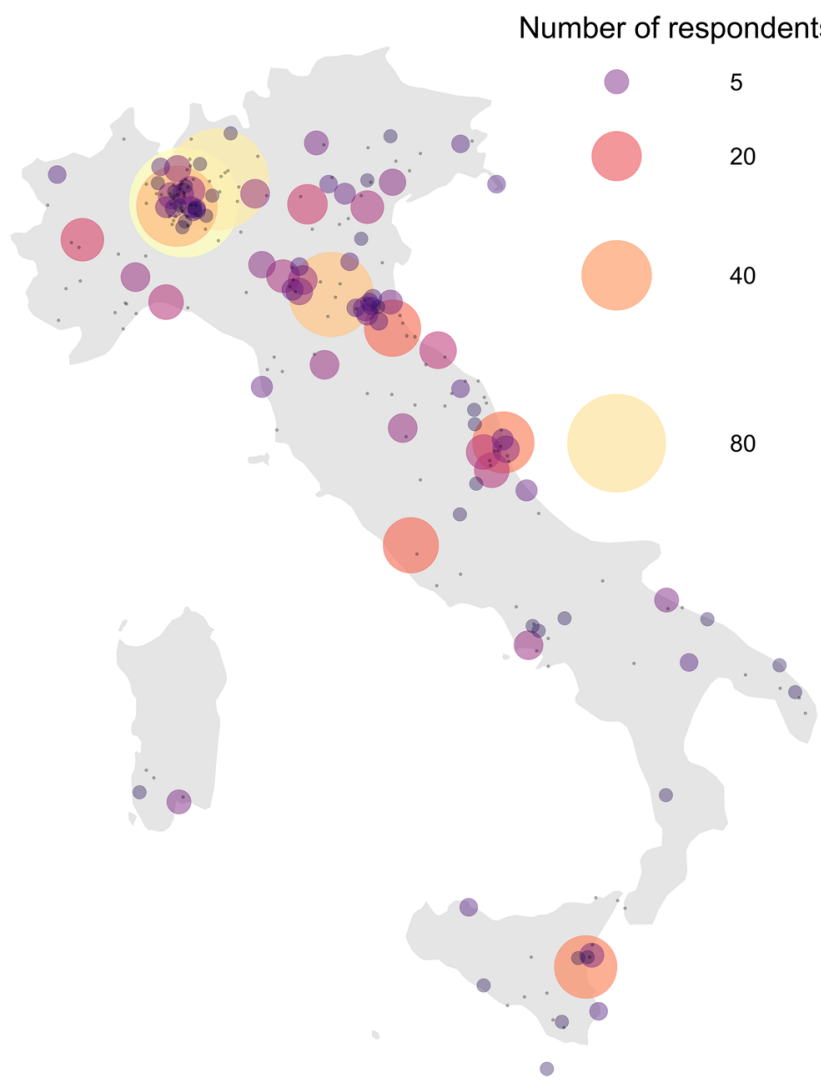

Fig. 2 Map of respondents to the online survey asked to state if they felt the need for it and, if so, to rate its importance. A 5-point Likert scale was used including the following responses: no/not applicable; yes, slightly important; yes, moderately important; yes, very important; yes, extremely important.

General Anxiety Questionnaire 7 (GAD-7). This is a widely used, validated self-report questionnaire that measures general anxiety disorders (Beard and Björgvinsson 2014; Spitzer et al. 2006). Each item is scored on a 4point Likert scale from 0 (symptoms not present) to 3 (symptoms present nearly every day) providing a score ranging from 0 to 21 . A sum score of $\geq 10$ indicates moderate symptoms. The internal consistency of the GAD-7 is very high with a Cronbach's alpha of 0.92 (Spitzer et al. 2006). An Italian translated version of the questionnaire was employed. The Italian version, downloadable on the PHQ Web site (https://www.phqscreeners. com), was used.

Intolerance of Uncertainty Scale, short form (IUS-12; Carleton et al. 2007). The IUS-12 is a 12-item self-report questionnaire that measures distressing reactions to uncertainty. For each item, participants have to indicate how strongly they agree with a statement (e.g., "I can't stand being taken by surprise") on a 5-point Likert scale ranging from 1 ("Not at all characteristic of me") to 5 ("Entirely characteristic of me"). This scale presents a good internal consistency with a Cronbach's alpha of 0.80 (Bottesi et al. 2015).

Table 1 Numerosity of respondents and mean and standard deviation of the AUC of compliance for the three hypothetical levels of risk, perceived risk over time, GAD-7, and IUS-12 for each group

\begin{tabular}{|c|c|c|c|c|c|c|c|c|c|c|c|c|c|}
\hline \multirow[t]{2}{*}{ Variable } & \multirow{2}{*}{$\begin{array}{l}\text { Total number }(N=931) \\
n(\%)\end{array}$} & \multicolumn{2}{|c|}{ AUC - $10 \%$ risk } & \multicolumn{2}{|c|}{ AUC $-50 \%$ risk } & \multicolumn{2}{|c|}{ AUC $-90 \%$ risk } & \multicolumn{2}{|c|}{ Perceived risk } & \multicolumn{2}{|c|}{ GAD-7 } & \multicolumn{2}{|c|}{ IUS-12 } \\
\hline & & $M$ & $S D$ & $M$ & $S D$ & $M$ & $S D$ & $M$ & $S D$ & $M$ & $S D$ & $M$ & $S D$ \\
\hline \multicolumn{14}{|l|}{ Gender } \\
\hline Male & $364(39.1)$ & 0.52 & 0.28 & 0.80 & 0.23 & 0.89 & 0.21 & 0.42 & 0.22 & 5.45 & 3.75 & 32.52 & 7.75 \\
\hline Female & 567 (60.9) & 0.55 & 0.31 & 0.80 & 0.26 & 0.87 & 0.25 & 0.47 & 0.21 & 8.10 & 4.72 & 34.89 & 9.10 \\
\hline \multicolumn{14}{|l|}{ Age (years) } \\
\hline $18-24$ & $330(35.4)$ & 0.53 & 0.29 & 0.80 & 0.22 & 0.90 & 0.19 & 0.46 & 0.21 & 7.88 & 4.71 & 35.30 & 8.42 \\
\hline $25-34$ & $339(36.4)$ & 0.52 & 0.29 & 0.81 & 0.25 & 0.88 & 0.23 & 0.44 & 0.22 & 6.95 & 4.54 & 34.30 & 8.41 \\
\hline $35-44$ & $106(11.4)$ & 0.51 & 0.31 & 0.81 & 0.25 & 0.89 & 0.23 & 0.43 & 0.22 & 6.20 & 4.29 & 31.25 & 8.59 \\
\hline $45+$ & $156(16.8)$ & 0.56 & 0.28 & 0.79 & 0.26 & 0.85 & 0.28 & 0.48 & 0.24 & 6.17 & 4.12 & 32.29 & 9.21 \\
\hline \multicolumn{14}{|l|}{ Income per year $(€)$} \\
\hline$<25,000$ & $335(36)$ & 0.54 & 0.30 & 0.81 & 0.24 & 0.89 & 0.23 & 0.44 & 0.22 & 7.24 & 4.51 & 34.26 & 9.00 \\
\hline $25,000-40,000$ & $265(28.5)$ & 0.54 & 0.29 & 0.81 & 0.23 & 0.89 & 0.20 & 0.48 & 0.22 & 7.26 & 4.52 & 34.22 & 8.85 \\
\hline $40,000-70,000$ & $200(21.5)$ & 0.51 & 0.29 & 0.80 & 0.24 & 0.89 & 0.22 & 0.43 & 0.21 & 7.05 & 4.57 & 34.50 & 8.03 \\
\hline $70,000-100,000$ & $70(7.5)$ & 0.47 & 0.29 & 0.75 & 0.30 & 0.82 & 0.30 & 0.40 & 0.22 & 5.87 & 4.61 & 31.27 & 8.50 \\
\hline $100,000+$ & $45(4.8)$ & 0.50 & 0.28 & 0.82 & 0.21 & 0.91 & 0.22 & 0.51 & 0.21 & 6.40 & 4.70 & 32.42 & 7.49 \\
\hline not available & $16(1.7)$ & 0.56 & 0.31 & 0.75 & 0.26 & 0.80 & 0.31 & 0.52 & 0.23 & 7.38 & 4.72 & 33.38 & 9.21 \\
\hline \multicolumn{14}{|l|}{ Education } \\
\hline Middle school or lower & $53(5.7)$ & 0.53 & 0.27 & 0.74 & 0.28 & 0.81 & 0.32 & 0.46 & 0.24 & 8.02 & 5.41 & 36.74 & 10.11 \\
\hline High school & $381(40.9)$ & 0.54 & 0.29 & 0.81 & 0.23 & 0.89 & 0.22 & 0.47 & 0.21 & 7.17 & 4.41 & 34.90 & 8.35 \\
\hline Bachelor's & $249(26.7)$ & 0.51 & 0.29 & 0.78 & 0.24 & 0.88 & 0.21 & 0.44 & 0.21 & 7.33 & 4.88 & 33.65 & 8.82 \\
\hline Master's or higher & $248(26.6)$ & 0.53 & 0.30 & 0.82 & 0.25 & 0.89 & 0.23 & 0.44 & 0.23 & 6.42 & 4.15 & 32.27 & 8.40 \\
\hline
\end{tabular}




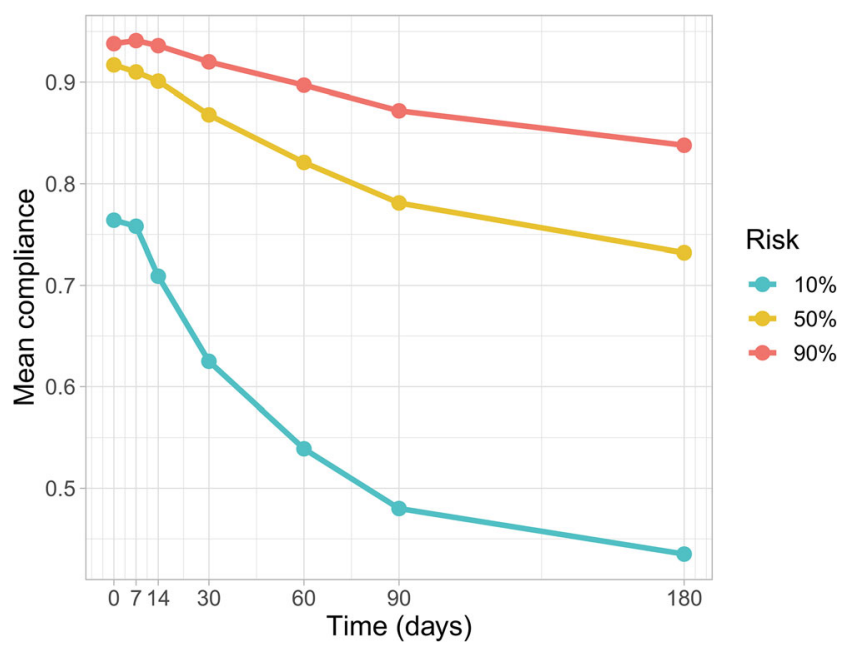

Fig. 3 Delay discounting of self-reported compliance with containment measures for three levels of hypothetical risk of contracting COVID-19

\section{Data analysis}

Several measures of delay discounting have been proposed; the two most commonly used are the $\mathrm{k}$ index of the hyperbolic equation (Mazur 1987) and the area under the curve (AUC; Myerson et al. 2001). In the present work the AUC method was employed, which has the advantage of not relying on an a priori mathematical function (e.g., hyperbolic) (Myerson et al. 2001). First, the values obtained on the acceptability of interrupting the isolation were normalized so that they ranged from 0 to 1 . Second, to obtain a curve corresponding to the degree of compliance, complementary values were computed by subtracting each value from 1 . The following scale representing the acceptability of isolation was therefore obtained: $0=$ "totally unacceptable"; $0.25=$ "not acceptable"; $0.5=$ "neutral"; $0.75=$ "acceptable"; 1 = "totally acceptable". Once the values representing the time points are also normalized, it is possible to obtain the degree of compliance for each hypothetical time series (see Fig. 1 for an example). A single compliance index ranging from 0 (minimum compliance) to 1 (maximum compliance) was then obtained through a trapezoidal numerical integration function that computes the AUC (as described by Myerson et al. 2001). The same procedure was repeated for each level of hypothetical risk for each participant. Lower AUC values correspond to steeper discounting rates while higher AUC values correspond to more stable compliance rates over time.

The same method was used to compute a single index of perceived risk over time for each respondent. Finally, values of generalized anxiety and intolerance of uncertainty were computed following the scoring procedure of each questionnaire. Statistical analyses were performed using SPSS version 20 (SPSS Inc., Chicago, IL).

\section{Results}

A total of 931 people responded to the survey $(60.9 \%$ females, $M_{\text {age }}=31.65$ years, $\mathrm{SD}=11.82$, range $=18-76$ ). The geographical distribution of respondents showed that $56.8 \%$ live in the two regions with the most reported positive cases (Lombardy and Emilia-Romagna) on the day the survey was launched (see Fig. 2).

The numerosity of respondents for each demographic category is shown in Table 1 along with the mean and standard deviation of the AUC of compliance at each level of risk.

The resulting delay discounting curve of compliance is shown in Fig. 3. People considered interrupting isolation more acceptable if the measures would be prolonged according to the risk level. A hyperbolic-like curve describes the delay discounting for an hypothesized $10 \%$ risk of contracting COVID-19, while the curves flatten considerably at 50 and $90 \%$ risks.

Differences in the AUC of compliance, perceived risk, generalized anxiety, and intolerance of uncertainty between males and females were investigated using a Mann-Whitney U test. Females showed significantly higher scores of generalized anxiety $\left(M d n_{F}=7, M d n_{M}=5\right), U=67,474, z=-8.95$, $p<0.001, r=-0.29$, intolerance of uncertainty $\left(M d n_{F}=35\right.$, $\left.M d n_{M}=33\right), U=87,355, z=-3.96, p<0.001, r=-0.13$, and perceived risk $\left(M d n_{F}=0.46, M d n_{M}=0.41\right) U=85,310, z=$ $-4.47, p<0.001, r=-0.15$, than males. It worth noting that a mean difference of almost three points in the GAD-7 overall score between males and females is all but negligible from a clinical point of view and that the mean score of females $(M=$ $8.1)$ is very close to the cutoff indicated for clinical relevance of anxiety symptoms (10). No significant differences were found in the AUC of compliance between genders. An independent-samples Kruskal-Wallis test was used to test

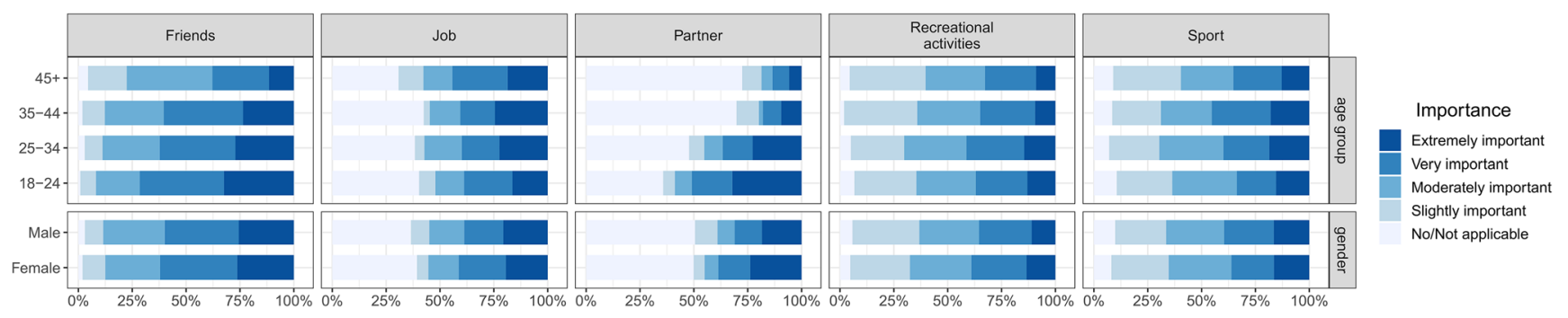

Fig. 4 Reported importance of the five considered psychological needs among different age groups and genders 


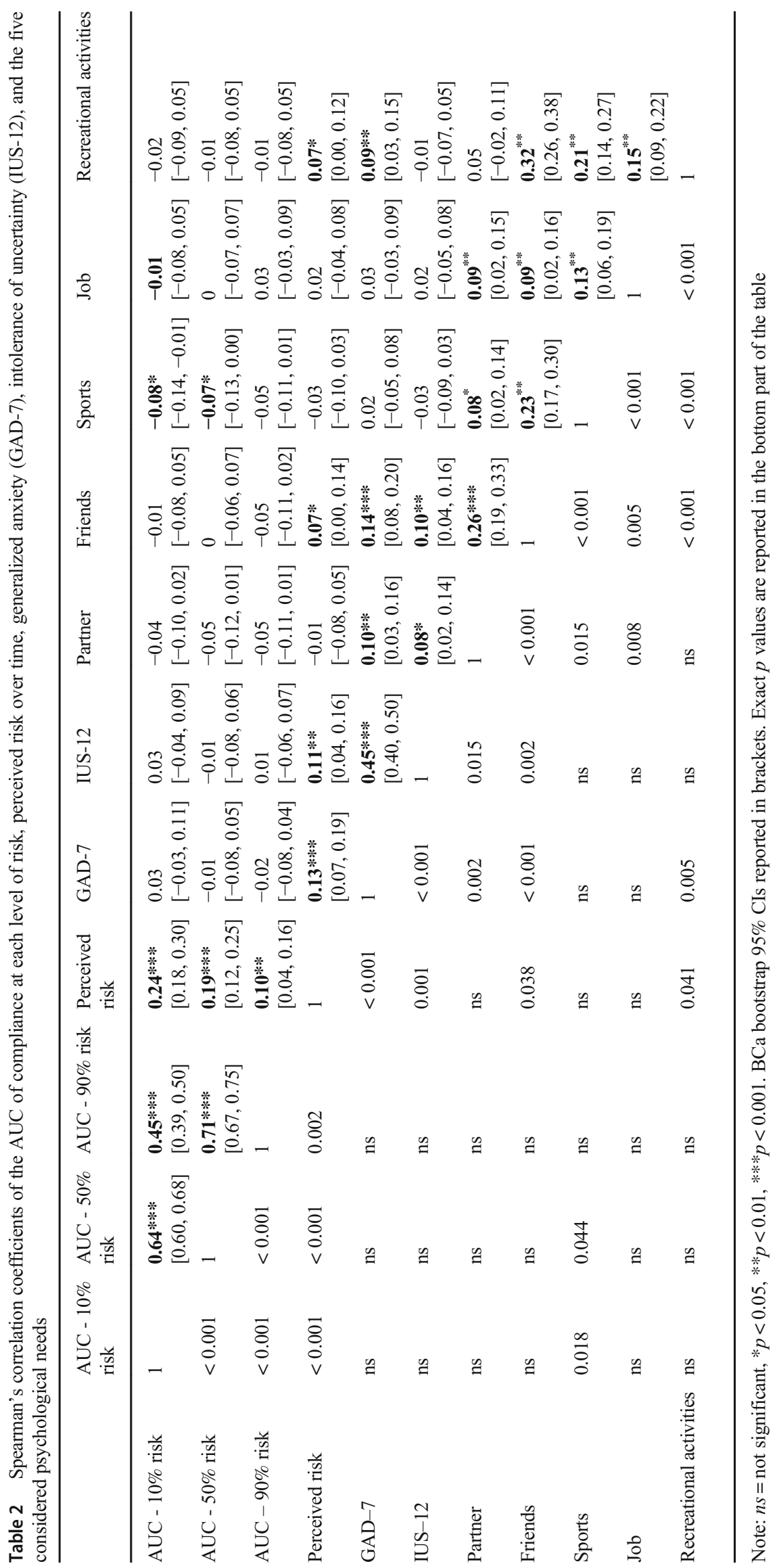


differences across groups based on age, income per year, and education: the level of anxiety was significantly affected by the age group $H(3)=21.70, p<0.001$, as well as the intolerance of uncertainty, $H(3)=22.59, p<0.001$; the income per year was significantly associated with anxiety $H(5)=11.27$, $p=0.046$, and perceived risk over time, $H(5)=15.00, p=$ 0.01 ; finally, education significantly affected the level of intolerance of uncertainty, $H(3)=22.48, p<0.001$, and the AUC of compliance with a 50\% risk, $H(3)=13.16, p=0.004$.

The distribution of answers regarding the psychological needs is represented in Fig. 4 for each age group and gender. It can be observed that younger people tend to report a higher need of closeness to the partner and friends. Also, females reported a slightly greater need of closeness to the partner than males. In general, the need to meet friends emerged as the most important among all the selected psychological needs.

A correlation analysis was performed to explore any association between considered variables. Table 2 shows the correlation coefficients and the significance of each pair of variables. Here, we highlight the main findings: higher values of AUCs of compliance were significantly associated with higher values of perceived risk at 10, 50, and 90\% hypothetical probability of contracting COVID-19, meaning that people who perceive a higher risk of infection tend to be more compliant with containment measures over time. Also, perceived risk was significantly related to generalized anxiety. Considering the relationship between compliance and specific needs, only sports significantly correlated with the compliance AUC at a hypothetical level of risk of $10 \%$ and $50 \%$; people who consider outdoor sports very important tend to have steeper discounting rates of compliance over time.

Finally, several psychological needs were significantly correlated with generalized anxiety and intolerance of uncertainty: the needs to meet one's partner and to meet friends were related with generalized anxiety and intolerance of uncertainty scores; also the need to meet friends correlated with anxiety and intolerance of uncertainty; the need for recreational activities was related only with GAD-7. People reporting stronger psychological needs also tended to be more anxious and less tolerant of uncertainty during the lockdown.

\section{Discussion}

The aim of the present study was to explore the compliance of people to unprecedented containment measures established by the Italian government to tackle the rapid spread of COVID-19 across the country. It is plausible to hypothesize that in case of a prolongation of the measures, people will start to be less compliant, displaying what is called delay discounting, which in this particular context can be described as the tendency to prefer the satisfaction of immediate needs (e.g., going out and meeting people) in the presence of a higher risk to health compared to adhering to safety behaviours (e.g., social isolation) and delaying the gratification of needs (Brooks et al. 2020). This situation is worsened by the high amount of uncertainty about the duration of the lockdown and the mental distress that social isolation and adaptation to big changes can cause.

Respondents to the survey showed a discounting pattern of compliance over time similar to those found in past studies (Lawless et al. 2013), with a steeper discounting rate in case of a low likelihood of contracting COVID-19. While the observed discounting rates do not vary across different demographic groups, it has been shown how women seem to be more distressed than men, showing higher levels of anxiety and intolerance of uncertainty, like other studies have found (Barari et al. 2020). However, it is not possible to establish whether this difference emerged as a consequence of the outbreak or was already present before. Also, males tended to believe that the risk of infection would decrease more rapidly compared to females.

As expected, perceived risk over time was positively associated with compliance over time. This implies that public health policy makers having an interest in promoting a high level of compliance among citizens could emphasize the risks of infection in public communications. However, enhancing the perception of risk among the population may have a psychological cost in terms of anxiety as these two dimensions also appeared to be correlated.

Despite the hypothesis that the urge to restart all the usual activities would affect the future trend of compliance, only outdoor sports was associated with a steeper delay discounting of compliance. However, other needs (friends and partner) presented a different relevance among age groups, potentially masking their effect on the overall reported trends of compliance. Moreover, the need to meet one's partner and friends has been shown to be associated with the severity of anxiety symptoms. These elements should be taken into account when a reduced risk of person-to-person spread of the disease will allow a progressive easing of restrictions to prioritize the satisfaction of those needs which might undermine compliance with social isolation anyway (e.g., doing outdoor sports) or cause mental distress (e.g., reuniting with one's partner and friends) compared with other less compelling needs (e.g., going to theaters and restaurants).

Further research is needed to highlight the causal relationships between the variables considered in this study and to promote strategies for improving compliance over time without exposing people to mental distress.

Acknowledgments We thank all the respondents for their willingness to provide data for this research project.

Authors' contributions All authors have made substantial contributions to this work and have been involved in drafting or revising the manuscript. They have read and approved the final manuscript. 
Funding The authors received no specific funding for this work.

\section{Compliance with ethical standards}

Ethics approval and consent to participate The present study was approved by the Ethics Committee of Sigmund Freud University, Vienna (reference code: RBMDKD5QALCJC487790; vote: 05.03.2020). Participation was voluntary, and written informed consent was obtained from each subject upon access the online survey.

\section{Consent for publication Not applicable.}

Disclosure statement The authors declare that they have no competing interests.

Availability of data and materials The datasets used and/or analysed during the current study are available from the corresponding author on reasonable request.

\section{References}

Amlung M, Petker T, Jackson J, Balodis I, Mackillop J (2016) Steep discounting of delayed monetary and food rewards in obesity: a meta-analysis. Psychol Med. https://doi.org/10.1017/ S0033291716000866

Amlung M, Marsden E, Holshausen K et al (2019) Delay discounting as a transdiagnostic process in psychiatric disorders: a meta-analysis. JAMA Psychiatry 76(11):1176-1186. https://doi.org/10.1001/ jamapsychiatry.2019.2102

Barari S, Caria S, Davola A et al (2020). Evaluating COVID-19 Public Health Messaging in Italy: Self-Reported Compliance and Growing Mental Health Concerns. Harvard University Working Paper

Barlow P, McKee M, Reeves A, Galea G, Stuckler D (2017) Timediscounting and tobacco smoking: a systematic review and network analysis. Int J Epidemiol 46(3):860-869. https://doi.org/10.1093/ije/ dyw233

Barlow P, Reeves A, McKee M, Galea G, Stuckler D (2016) Unhealthy diets, obesity and time discounting: a systematic literature review and network analysis. Obes Rev 17(9):810-819. https://doi.org/10. 1111/obr.12431

Beard C, Björgvinsson T (2014) Beyond generalized anxiety disorder: psychometric properties of the GAD-7 in a heterogeneous psychiatric sample. J Anxiety Disorders 28(6):547-552. https://doi.org/10. 1016/j.janxdis.2014.06.002

Bickel WK, Athamneh LN, Basso JC, Mellis AM, DeHart WB, Craft WH, Pope D (2019) Excessive discounting of delayed reinforcers as a trans-disease process: update on the state of the science. Curr Opin Psychol 30:59-64. https://doi.org/10.1016/j.copsyc.2019.01.005

Bottesi G, Ghisi M, Novara C, Bertocchi J, Ilaria MB, Dominicis D, Freeston MH (2015) Intolerance of uncertainty scale (IUS-27 and IUS-12): Two preliminary studies. Psicoterapia Cognitiva e Comportamentale 21(3)

Brooks SK, Webster RK, Smith LE, Woodland L, Wessely S, Greenberg N, Rubin GJ (2020) The psychological impact of quarantine and how to reduce it: rapid review of the evidence. Lancet 395(10227):912-920. https://doi.org/10.1016/S0140-6736(20) 30460-8

Bruce JM, Bruce AS, Catley D et al (2016) Being kind to your future self: probability discounting of health decision-making. Ann Behav Med 50(2):297-309. https://doi.org/10.1007/s12160-015-9754-8

Bruce JM, Bruce AS, Lynch S et al (2018) Probability discounting of treatment decisions in multiple sclerosis: associations with disease knowledge, neuropsychiatric status, and adherence. Psychopharmacology 235(11):3303-3313. https://doi.org/10.1007/ s00213-018-5037-y

Bults M, Beaujean DJMA, De Zwart O et al (2011) Perceived risk, anxiety, and behavioural responses of the general public during the early phase of the influenza A (H1N1) pandemic in the Netherlands: Results of three consecutive online surveys. BMC Public Health, 11. https://doi.org/10.1186/1471-2458-11-2

Carleton RN, Norton MAPJ, Asmundson GJG (2007) Fearing the unknown: a short version of the intolerance of uncertainty scale. $\mathrm{J}$ Anxiety Disorders 21(1):105-117. https://doi.org/10.1016/j. janxdis.2006.03.014

Cava MA, Fay KE, Beanlands HJ, McCay EA, Wignall R (2005) Risk perception and compliance with quarantine during the SARS outbreak. J Nurs Scholarsh 37(4):343-347. https://doi.org/10.1111/j. 1547-5069.2005.00059.x

Daugherty JR, Brase GL (2010) Taking time to be healthy: predicting health behaviors with delay discounting and time perspective. Personal Individ Differ 48(2):202-207. https://doi.org/10.1016/j. paid.2009.10.007

Garza KB, Ding M, Owensby JK, Zizza CA (2016) Impulsivity and fastfood consumption: a cross-sectional study among working adults. J Acad Nutr Diet. https://doi.org/10.1016/j.jand.2015.05.003

Hayashi Y, Miller K, Foreman AM, Wirth O (2016) A behavioral economic analysis of texting while driving: delay discounting processes. Accid Anal Prev. https://doi.org/10.1016/j.aap.2016.08.028

Jin YH, Cai L, Cheng ZS et al (2020) A rapid advice guideline for the diagnosis and treatment of 2019 novel coronavirus (2019-nCoV) infected pneumonia (standard version). Military Med Res 7(1):123. https://doi.org/10.1186/s40779-020-0233-6

Johnson MW, Johnson PS, Herrmann ES, Sweeney MM (2015) Delay and probability discounting of sexual and monetary outcomes in individuals with cocaine use disorders and matched controls. PLoS One 10(5):1-21. https://doi.org/10.1371/journal.pone.0128641

Jones JH, Salathé M (2009) Early assessment of anxiety and behavioral response to novel swine-origin influenza a(H1N1). PLoS One 4(12): 2-9. https://doi.org/10.1371/journal.pone.0008032

Lawless L, Drichoutis AC, Nayga RM (2013) Time preferences and health behaviour: a review. Agricul Food Econ 1(1):17. https://doi. org/10.1186/2193-7532-1-17

Leung GM, Ho LM, Chan SKK et al (2005) Longitudinal assessment of community psychobehavioral responses during and after the 2003 outbreak of severe acute respiratory syndrome in Hong Kong. Clin Infect Dis 40(12):1713-1720. https://doi.org/10.1086/429923

Li Q, Guan X, Wu P et al (2020) Early transmission dynamics in Wuhan, China, of novel coronavirus-infected pneumonia. N Engl J Med. https://doi.org/10.1056/nejmoa2001316

Mazur JE (1987) An adjusting procedure for studying delayed reinforcement. In: Commons ML, Mazur JE, Nevin JA, Rachlin H (eds) Quantitative analyses of behavior: the effect of delay and of intervening events on reinforcement value, vol 5. Erlbaum, Hillsdale, pp $55-73$

Mohammadi M, Meskini M, do Nascimento Pinto AL (2020) 2019 novel coronavirus (COVID-19) overview. J Public Health, 9(Cdc). https:// doi.org/10.1007/s10389-020-01258-3

Myerson J, Green L, Warusawitharana M (2001) Area under the curve as a measure of discounting. J Exp Anal Behav 76(2):235-243. https:// doi.org/10.1901/jeab.2001.76-235

Odum AL, Becker RJ, Haynes JM et al (2020) Delay discounting of different outcomes: review and theory. J Exp Anal Behav:1-23. https://doi.org/10.1002/jeab.589

Rosati AG, Stevens JR, Hare B, Hauser MD (2007) The evolutionary origins of human patience: temporal preferences in chimpanzees, bonobos, and human adults. Curr Biol 17(19):1663-1668. https:// doi.org/10.1016/j.cub.2007.08.033 
Samuelson PA (1937) A note on measurement of utility. Rev Econ Stud 4(2): 155 . https://doi.org/10.2307/2967612

Sheffer CE, Miller A, Bickel WK et al (2018) The treasure of now and an uncertain future: delay discounting and health behaviors among cancer survivors. Cancer 124(24):4711-4719. https://doi.org/10. 1002/cncr.31759

Spitzer RL, Kroenke K, Williams JBW, Löwe B (2006) A brief measure for assessing generalized anxiety disorder: the GAD-7. Arch Intern Med 166(10):1092-1097. https://doi.org/10.1001/archinte.166.10. 1092

Steward T, Mestre-Bach G, Fernández-Aranda F et al (2017) Delay discounting and impulsivity traits in young and older gambling disorder patients. Addict Behav 71:96-103. https://doi.org/10.1016/j. addbeh.2017.03.001

Story GW, Vlaev I, Seymour B, Darzi A, Dolan RJ (2014) Does temporal discounting explain unhealthy behavior? A systematic review and reinforcement learning perspective. Frontiers in Behavioral
Neuroscience 8(MAR):1-20. https://doi.org/10.3389/fnbeh.2014. 00076

WHO (2020) Report of the WHO-China Joint Mission on Coronavirus Disease 2019 (COVID-19). https://www.who.int/docs/defaultsource/coronaviruse/who-china-joint-mission-on-covid-19-finalreport.pdf. Accessed 14 April 2020

Wilder-Smith A, Freedman DO (2020) Isolation, quarantine, social distancing and community containment: pivotal role for old-style public health measures in the novel coronavirus (2019-nCoV) outbreak. J Travel Med 27(2):1-4. https://doi.org/10.1093/jtm/taaa020

Zhang J, Liu P, Wang M et al (2020) The clinical data from 19 critically ill patients with coronavirus disease 2019: a single-centered, retrospective, observational study. J Public Health:2-5. https://doi.org/ 10.1007/s10389-020-01291-2

Publisher's note Springer Nature remains neutral with regard to jurisdictional claims in published maps and institutional affiliations. 